\title{
STUDY ON WATER SEEPAGE LAW OF RAW COAL DURING LOADING PROCESS
}

\author{
Meng Junqing, Nie Baisheng \\ School of Resource and Safety Engineering, China University of Mining \& \\ Technology(Beijing), Beijing 100083, China \\ State Key Lab of Coal Resources and Safe Mining (China University of Mining and \\ Technology), Beijing 100083, China \\ mengjunqing711@163.com
}

\begin{abstract}
In order to reveal the water seepage law of raw coal during different loading process, the gravity constant load seepage experimental system is developed and used in this paper. The water seepage law of raw coal during different loading process was tested. The mathematical model of axial strain-damage-permeability coefficient during the loading process is proposed based on the Wei-bull distribution of coal damage. According to the water seepage experiments and results analysis, the following conclusions are gotten. Under the same experimental conditions, with the increasing of axial pressure, the permeability coefficient of coal sample has a distinct decrease trend, and then an increase trend when reached the extreme point. The same trend of permeability coefficient-strain curves and stress-strain curve of the raw coal samples under different axial pressure are got-ten, that mean the permeability coefficient is closely related to the damage evolution process. The water seepage law of raw coal during different loading process can be described by the mathematical model of axial strain-damage-permeability coefficient, and its parameters can be obtained easily. This research is important for revealing the mechanism of coal seam water seepage, guiding field coal seam water infusion, controlling mine water hazard, preventing coal mine disasters.
\end{abstract}

Keywords- Raw coal, Permeability coefficient, Stress, Damage, Loading process

\section{INTRODUCTION}

The permeability of coal seam is generally affected by the complex geological conditions. The stress distributions of coal body are non-uniform in front of the working face; they are distressed zone, stress concentration zone and original stress zone from outside to inside of working face. The coal deformation with the moving of working face due to the concentrated stress transfer to the deep in front of the working face. So the stress distributions in front of the working face are dynamic change. Thus the permeability coefficient of raw coal and rock is changed. Coal seam water infusion is one of the most important measures to prevent coal and gas outbursts. High pres-sure coal seam water infusion is injecting high pressure water to coal seam in front of working face through drilling, in order to change the mechanical properties, the seepage properties and stress state of coal seam, a corresponding change in the coal and gas outburst excitation and occurrence conditions, and thus to prevent or decrease coal and gas outburst [1]. The permeability coefficient is an important index to influence the 
effect of coal seam water infusion. Study on water seepage law of raw coal during loading process can provide a theoretical basis for effective guiding the coal seam water infusion. The quantitative evaluation of the hydraulic characteristics and fluid seepage of the fractured rock mass are researched by scholars of domestic and foreign since the nineteen fifties. The hydraulic characteristics and fluid seepage of the fractured rock mass were studied by Romm (1966), Snow (1969), Louis (1974), Wittke (1970), and the model of seepage in fractured rock mass was proposed. The law between stress and seepage was gotten through experiment and theory research by scholars of domestic and foreign [2-6]. But it is also found that not enough has been done the permeability coefficient law of raw coal during the loading process. The components and micro structures of coal are very different with the different sedimentary rocks due to the different depositional environments. So the similarities and differences of permeability characteristics of coal and other sedimentary rocks still need to be researched [7-14]. This research provides an experimental and theoretical basis for the analysis of solidliquid coupling effect in the coal mining process.

\subsection{Apparatus}

\section{EXPERIMENTAL}

The coal sample is loaded during experiments by the gravity constant load creep seepage experimental apparatus with the self-made CSCG-160 type, this experiment apparatus can be shown in Fig.1. The CSCG-160 gravity constant load creep seepage experimental apparatus use gravity constant load pressure for triaxial loading. It is mainly includes five parts of the loading system, water filling system, vacuum system, control system and data acquisition system. The holder used in this experiment can be shown in Fig.2. The axial pressure is applied by an axial piston with fluid-filled pressure, and the amount of axial displacement can be collected through the axial piston displacement. The confining pressure is applied by the high pressure water squeezing pouches wrapped coal samples. The coal sample in the holder is loaded by loading system to the needed axial pressure and confining pressure. Open and debugging the data acquisition system, and then set the water pressure achieved a certain pressure value through the water filling system. The different triaxial stress states are adjusted through the control system. The permeability coefficient can be calculated by measuring stable flow of water under different stress states.

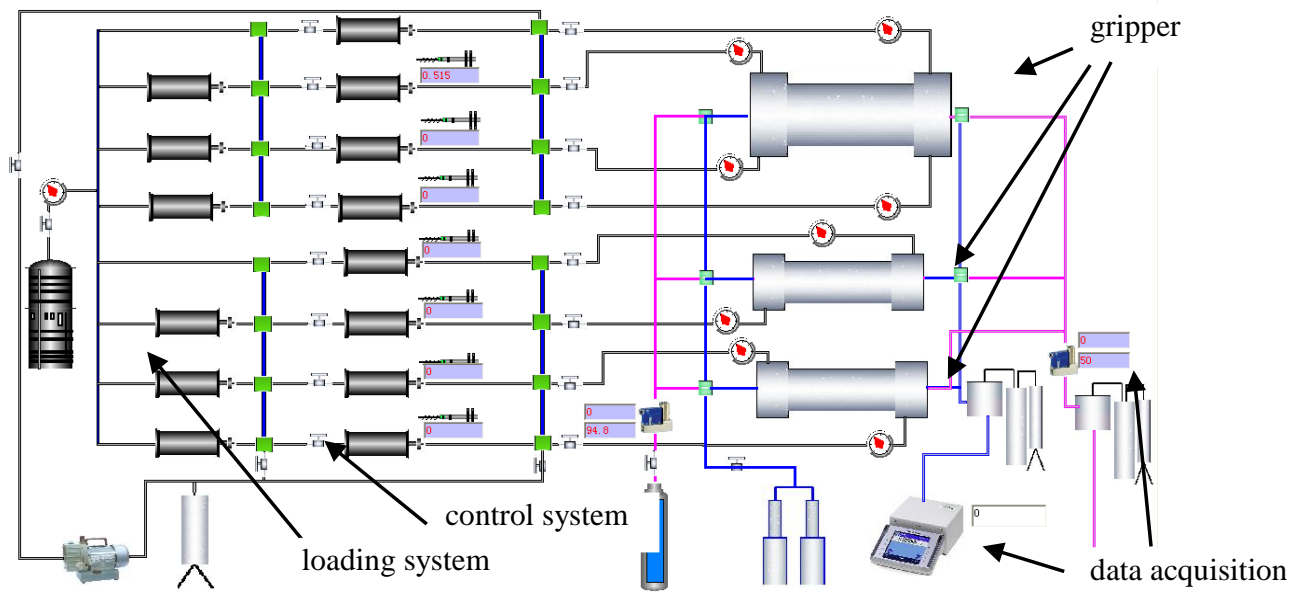

Figure 1. Flow chart of apparatus 
Constant flow pump with SHH-250-50 (Double cylinder) (Fig.3) is used in this experiment for seepage water pressure. The different water pressure with the different load to the inlet end of coal body can be gotten by the control system of the constant flow pump.

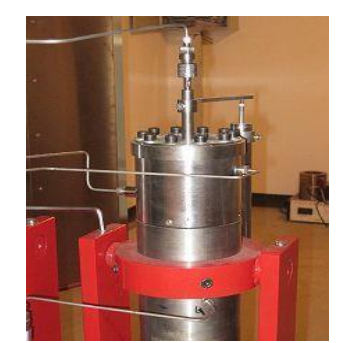

Figure 2. Gripper of coal and rock

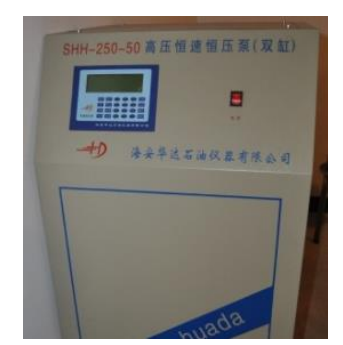

Figure 3. Constant flow pump

\subsection{Programs}

Raw coal samples are taken from Xuandong mine of china with outburst-prone. The coal samples are gotten through intensive drilling on one end of the body of a large lump raw coal to avoid different burial depth, the stress history and stress state of coal seam. At the same time, the water is used when drilling for preventing the large thermal stress produced during core drilling in coal. The size of coal samples is International Society for Rock Mechanics (ISRM) recommended size, $\Phi 50 \mathrm{~mm} \times 100 \mathrm{~mm}$ and the surface flatness error of ends less than $0.02 \mathrm{~mm}$, the coal samples can be shown in Fig.4.

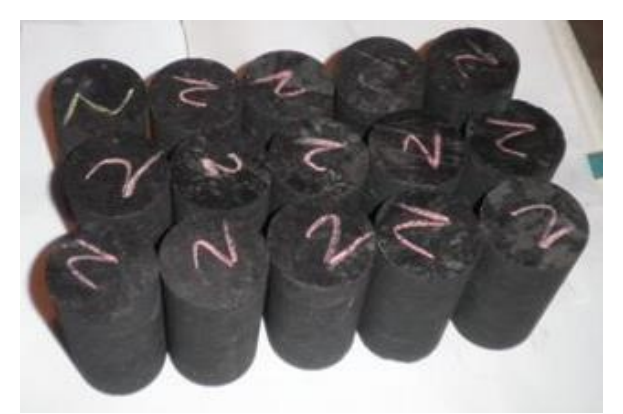

Figure 4. Coal sample

Steady state method is used in this experiment for testing the permeability coefficient of the raw coal, this method has higher precision. The different pressure at both ends of the raw coal sample during experiment is fixed. The flow discharge of the outlet end is measured for measuring permeability coefficient of the raw coal. The calculation equation of the permeability coefficient of measurement point is obtained according to the Darcy's law, such as Eq. (2.1) [15-17].

$$
K=\frac{q_{w} \mu_{w} l \times 10^{2}}{A\left(p_{1}-p_{0}\right)}
$$

Where, $K$ is the permeability coefficient, md. $q_{w}$ is flow discharge, $\mathrm{cm}^{3} / \mathrm{s} . \mu_{w}$ is the water viscosity coefficient, $m P a \cdot s . l$ is the sample length, $\mathrm{cm} . A$ is specimen cross-sectional 
area, $\mathrm{cm}^{2} . p_{1}$ is the imported water pressure, MPa. $p_{0}$ is the measurement point atmospheric pressure, MPa.

The permeability coefficients of outburst-prone raw coal sample with the increasing of axial pressure are obtained through this seepage experiment.

(1) The coal sample is dried in the drying oven. Then the coal sample is placed in the triaxial hydraulic holder, axial pressure and confining pressure are loaded to the set value, and exhaust air.

(2) Open the constant flow pump and the water pressure is to the set value through adjusting the valve. Outlet flow value of water is gotten from balance, and then axial pressure is gradually increasing.

(3) Confining pressure and water pressure is fixed, axial pressure is progressively increased, and the relationship between the strain-stress and strainpermeability coefficient of raw coal samples are gotten, until the end of this experiment.

\subsection{Results}

Experimental temperature, confining pressure constant, the relationship between the strain-stress and strain-permeability coefficient of raw coal samples of Xuandong mine are gotten at different axial pressure through this experiment.

The curve of strain-stress and strain-permeability coefficient of raw coal samples from Xuandong mine of china with axial pressure gradually increasing and confining pressure of $3.5 \mathrm{Mpa}$ when water pressure is $2.15 \mathrm{MPa}$ can be shown in Fig.5, the experimental temperature is $11.5^{\circ} \mathrm{C}$.

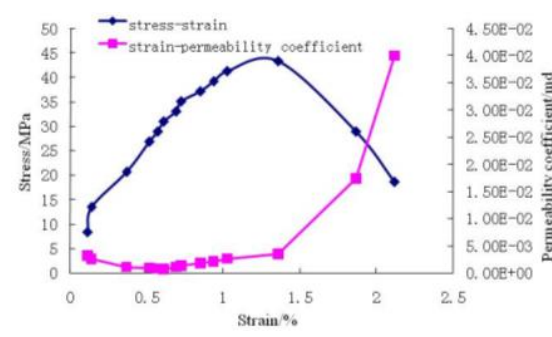

(XD-1)

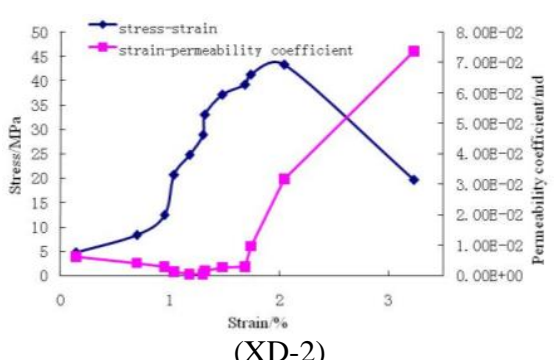

(XD-2)

Figure 5. Permeability coefficient at different axial pressure

\subsection{Discussion}

The relationship between the axial stress-strain and axial stress-permeability coefficient of raw coal samples are gotten through this experiment. Under the same experimental conditions, as the axial pressure increasing, the micro porous of coal body closure, the permeability coefficient exhibits a decrease trend. The elastic-plastic deformation of coal continues to increase with the increasing of axial pressure, and a slowly increase trend when reached the extreme point. Then the permeability coefficient increases rapidly to a maximum. The relationship of axial pressure and permeability coefficient of the coal samples come from Xuandong mining have shown similar trends.

The curve of strain-permeability coefficient of whole process with loading is divided into three sections for the evolution law of permeability coefficients with loading process. The first section is coal compression phase that is shown in Fig.6 of section $\mathrm{AB}$, the permeability coefficient exhibits a decrease trend with the increasing of axial pressure. The second sections is elastic-plastic deformation damage phase that is shown in Fig. 6 of section BC, the permeability coefficient exhibits a slowly increase 
trend when reached the extreme point, and then increases rapidly to a maximum with the increasing of axial pressure. The third section is after peak seepage phase. The mathematical models of two sections are proposed according to the evolution law of strain-permeability coefficients with loading process.

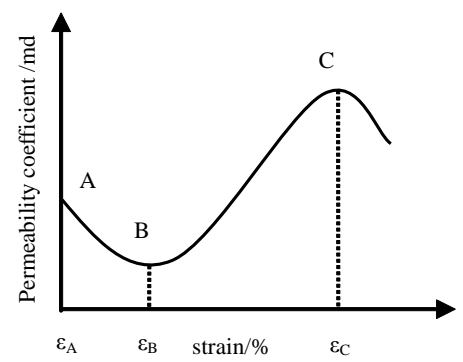

Figure 6. Curve of strain-permeability coefficient

It is difficult to give a unified analytic expression for water seepage of raw coal with loading process due to many impact factors on permeability coefficient. Therefore, the laboratory study on water seepage of coal under different stress level can provide theoretical basis for the analysis of water seepage law of coal seam.

\section{MATHEMATICS EVOLUTION MODEL}

(1) Definition of damage variable D of coal and rock

The depth three-dimensional images of the section magnified 100 times from Xuandong mine coal sample XD-2 after the experiment is shown in Fig.7, which can be seen that the coal pore is very developed, surface is smooth, crack propagation distributed at random, a typical outburst coal fracture characteristics is shown. Damage evolution can be considered to obey statistical distribution.

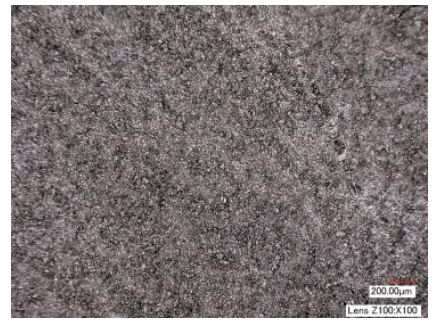

(XD-2, $\times 100)$

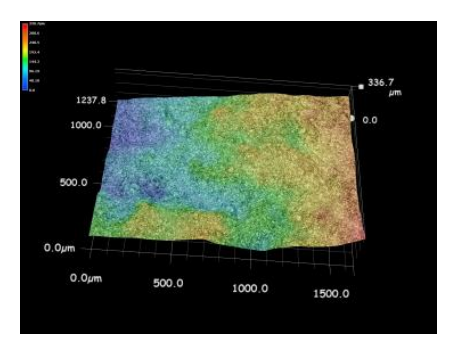

$(\mathrm{XD}-2, \times 100)$

Figure 7. 3D images of coal sample

The damage of coal under axial loading as "damage field" continuum media, the damage is used to describe the damage evolution law of coal under axial loading in this paper. Microscopic defects (such as large number of micro cracks and micro voids etc.) can be seen from the depth three-dimensional images of the section magnified 100 times from Xuandong mine coal sample XD-2 after the experiment. These microscopic defects distributed at random and a discrete state, the damage of coal sample can be defined based on the Weibull distribution [18], as shown in Eq. (3.1). 


$$
D=1-\exp \left(-\left(\frac{\varepsilon}{\varepsilon_{0}}\right)^{m}\right) \quad\left(\varepsilon_{B} \leq \varepsilon \leq \varepsilon_{C}\right)
$$

(2) Permeability coefficient evolution model of section AB

The predecessors have done a lot of research in the relationship of stress and permeability coefficient. The relationship between stress and permeability coefficient was gotten by Peuga and Louis through a large number of pumping water experiments in 1974[19], as shown in Eq. (3.2).

$$
k=k_{0} \exp (-\alpha \sigma)
$$

Where, $k$ is permeability coefficient, $\sigma=\gamma h-p, \gamma h$ is the gravity of overlaying strata, $p$ is pore pressure, $\alpha$ is constant.

The relationship between the volume stress and permeability coefficient of raw coal sample was obtained through experiment by Zhao Yangsheng[20-22], as shown in Eq. (3.3).

$$
k=a \exp (-b \Theta+c p)
$$

Where $a, b, c$ are fitting coefficients, different coal samples having different fitting coefficients. $\Theta$ is volume stress, $\Theta=\sigma_{1}+\sigma_{2}+\sigma_{3}$.

Combined Eq. (3.2) and Eq. (3.3) can be seen, the permeability coefficient $k$ obey negative exponent attenuation rule with the increasing of volume stress $\Theta$. The impact of stress on the permeability coefficient is mainly through the effect of strain to achieve.

Summing up the results of previous studies can be seen, confining pressure and water pressure constant, the permeability coefficient and axial stress obey negative exponent attenuation rule, as shown in Eq. (3.4).

$$
k=A \exp \left(-B \sigma_{1}\right)
$$

Where $k$ is the permeability coefficient and $A, B$ are constants.

Assuming confining pressure and pore pressure are constant, constitutive equation of coal body at axial loading process as shown in Eq. (3.5).

$$
\sigma_{1}=E \varepsilon_{1}
$$

Where, $\sigma_{1}$ is axial stress, $E$ is elastic modulus, $\varepsilon_{1}$ is axial displacement.

Eq. (3.6) can be obtained through substituted Eq. (3.5) in Eq. (3.4).

$$
k=A \exp \left(-B E \varepsilon_{1}\right)=A \exp \left(-B^{\prime} \varepsilon_{1}\right)\left(\varepsilon_{A} \leq \varepsilon_{1} \leq \varepsilon_{B}\right)
$$

Where, $B^{\prime}=B E$.

(3) Permeability coefficient evolution model of section BC

The jumping increase law of permeability coefficient with the loading can be seen after the occurrence of plastic strain of the coal. It is difficult use a certain theory to describe this rule. The law of stress-strain-permeability coefficient was studied by Li Shiping [23], and the law of strain-permeability coefficient of rock at different stressstrain section can be expressed through the polynomial function. The law of strainpermeability coefficient of Baodian mine coal sample was studied by Yang Yongjie $[24,25]$ through curve fitting method of the experimental data, and piecewise fitting function is gotten.

Based on statistical damage mechanics theory, the mathematical model of axial strain-damage-permeability coefficient is proposed based on the previous studies in this 
paper. The seepage law of coal is analyzed with the loading damage stages. The jumping increase law of permeability coefficient with the loading can be described through Eq.(3.7).

$$
k=k_{1} l^{n c}
$$

Where, $k$ is permeability coefficient, $k_{1}$ is the permeability coefficient at point $\mathrm{B}$ of the curve of strain-permeability coefficient, $l^{n}$ is the change magnitude of the permeability coefficient, $c$ is the damage coefficient.

The relationship shown as the Eq. (3.8) of $c$ and damage meet first-order exponential decay function is assumed in this mathematical model in order to reduce the error of calculation results and experimental data.

$$
c=A_{0} e^{-D / \alpha}+B_{0}
$$

Where, $D$ is damage, can be obtained through Eq.(3.1). $\alpha$ is fitting coefficient, $A_{0}=\frac{1}{e^{-1 / \alpha}-1}, B_{0}=-\frac{1}{e^{-1 / \alpha}-1}$.

The fitting precision of calculation results and experimental data can be improved through adjusting the parameter $\alpha$ in the Eq. (3.8). The calculation result of $c$ when $\alpha$ are respectively $0.3,0.5,1$ and 10 based on the Eq. (3.8) are shown in Fig.8. It can be seen from the Fig. 8 the variation trend of $c$ changed through change fitting coefficient $\alpha$. The value $\alpha$ is smaller, the more obvious of nonlinear between the damage and $c$. The value $\alpha$ is greater, the more obvious of linear relationship between the damage and damage coefficient $c$.
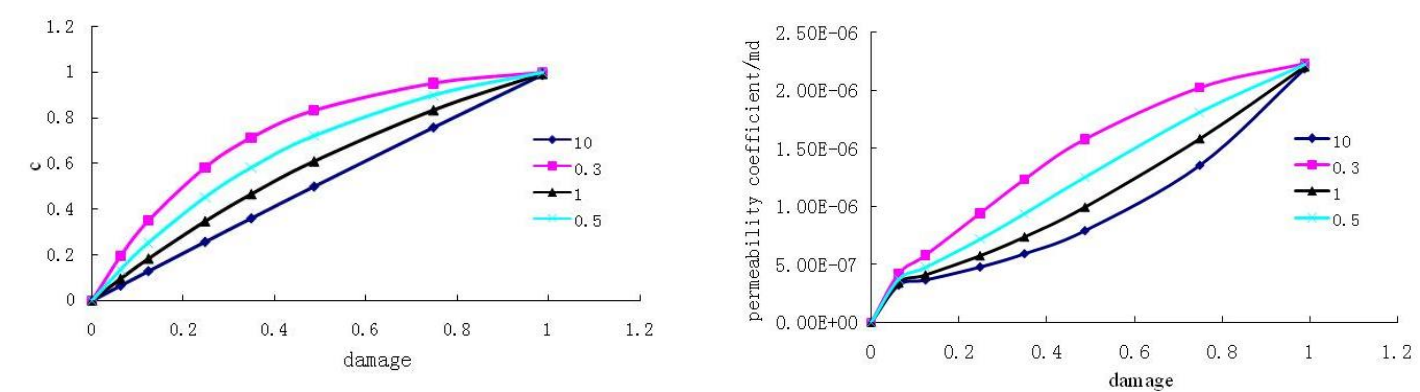

Figure 8. Curve of damage-c value Fig.9 Curve of damage-permeability coefficient

The calculation result of $k$ when $\alpha$ are respectively $0.3,0.5,1$ and 10 based on the Eq. (3.7) and Eq. (3.8) are shown in Fig.9. It can be seen from the Fig.8 the variation trend of $k$ changed through change fitting coefficient $\alpha$. The value $\alpha$ is smaller; the permeability coefficient obvious exhibits a greatly increasing, and then slowly increases with the increasing of damage.

The permeability coefficients obvious exhibit a greatly increasing with the accumulation of strain, and then slowly increasing when damage developed to a certain extent. This can be seen from the curve of damage-permeability coefficient are shown in Fig.9. The reason is the accumulation of damage with the formation of new transfixion. 
(4) The model parameters based on experimental data

The model parameters of mathematical model of strain-damage-permeability coefficients are gotten according to the experimental data of permeability coefficient at different axial pressure of coal mine samples. The model parameters can be obtained easily, and the experimental values and calculated values curve of strain-permeability coefficient are analyzed.

The function axial strain-damage-permeability coefficients of different Xuandong mine coal samples are respectively shown as the Eq.(3.9) and Eq.(3.10) according to the experimental data, where $\alpha=5, \quad m=10, n=2, l=7.7, l=10.5$, the experimental values and calculated values curve of strain-permeability coefficient are shown in Fig.10.

$$
\left\{\begin{array}{l}
k_{A B}=(3.9 E-3) \exp (-2.9589 \varepsilon),(0.0011 \leq \varepsilon \leq 0.0057) \\
k_{B C}=(6.8 E-4) 7.7^{(2 c)},(0.0057 \leq \varepsilon \leq 0.021)
\end{array}\right.
$$

Where, $c=A_{0} e^{-D / 5}+B_{0}, D=1-\exp \left(-\left(\frac{\varepsilon}{0.018}\right)^{10}\right), A_{0}=\frac{1}{e^{-1 / 5}-1}, B_{0}=-\frac{1}{e^{-1 / 5}-1}$.

$$
\left\{\begin{array}{l}
k_{A B}=(9.4 E-3) \exp (-2.4872 \varepsilon),(0.0015 \leq \varepsilon \leq 0.0118) \\
k_{B C}=(2.86 E-4) 10.5^{(2 c)},(0.0118 \leq \varepsilon \leq 0.0205)
\end{array}\right.
$$

Where, $c=A_{0} e^{-D / 5}+B_{0}, D=1-\exp \left(-\left(\frac{\varepsilon}{0.017}\right)^{10}\right), A_{0}=\frac{1}{e^{-1 / 5}-1}, B_{0}=-\frac{1}{e^{-1 / 5}-1}$.

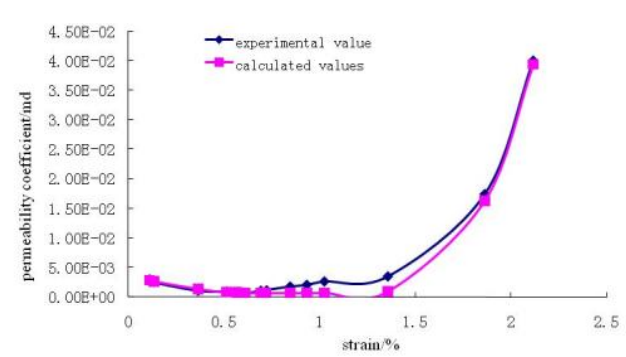

(XD-1)

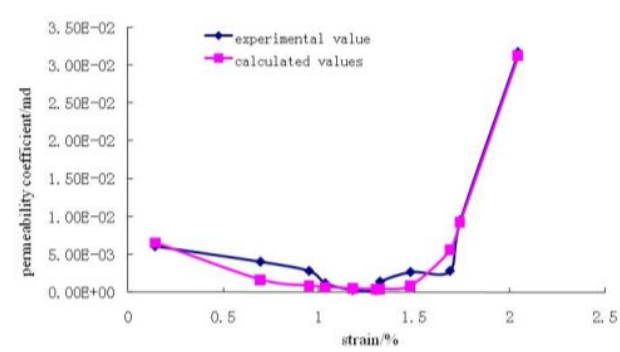

(XD-2)

Figure 10. experimental values and calculated values curve of strain-permeability coefficient

The experimental data of permeability coefficient at different axial pressure of Baodian coal mine samples are used for fitting analysis in addition to the literature of [23]. The model parameters of different Baodian mine coal sample according to the experimental data are listed in Tab.1. The experimental values and calculated values curve of strain-permeability coefficient are shown in Fig.11. It is can be seen the calculation values of model and experimental values have the good corresponding effect. The model parameters can be obtained easily, and the practical application is convenient.

Table 1. Fitted values of model parameters

\begin{tabular}{ccccc}
\hline parameter & $\alpha$ & $m$ & $n$ & $l$ \\
\hline BD-1 & 10 & 5 & 1 & 8.5 \\
BD-2 & 10 & 5 & 1 & 7.3 \\
BD-3 & 10 & 5 & 1 & 6.8 \\
\hline
\end{tabular}




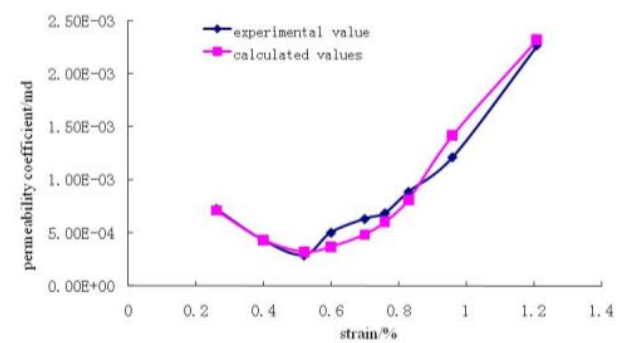

(BD-1)

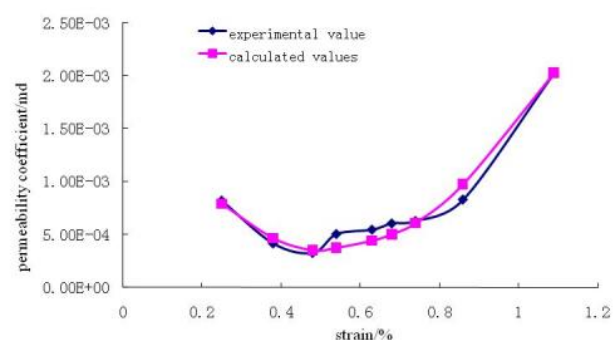

(BD-2)

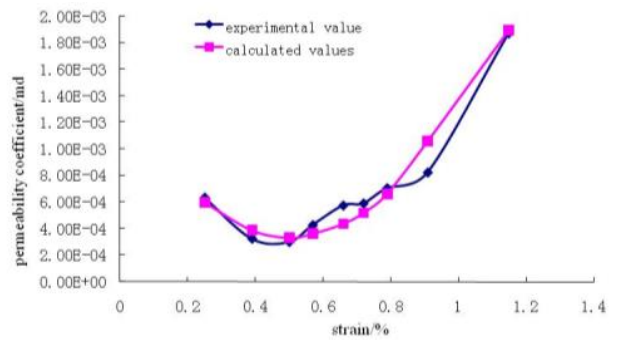

(BD-3)

Figure 11. Experimental values and calculated values curve of strain-permeability coefficient

\section{CONCLUDING REMARKS}

According to the water seepage experiments, the following conclusions can be drawn.

(1) The relationship between the axial pressure and permeability coefficient are gotten through experimental study. The results show that the same trend of permeability coefficient-strain curve and stress-strain curve of the raw coal samples is gotten at different axial pressure, that the variation of permeability coefficient is closely related to the damage evolution process. The experimental study of permeability coefficient under different axial pressure has important significance for further analysis of the evolution law of permeability coefficient.

(2) According to the experimental results, the mathematical model of axial strain-damage-permeability coefficient is proposed based on the Weibull distribution of coal damage. The results indicate that, the water seepage law of coal during different loading process can be described by the mathematical model; its parameters can be obtained easily. This research is very important for revealing the mechanism of coal seam water seepage, guiding field coal seam water infusion, controlling mine water hazard, preventing coal mine disasters.

\section{ACKNOWLEDGEMENT}

This work is financially supported by the Fundamental Research Funds for the Central Universities (No. 2011QZ02); National Natural Science Foundation of China (No. 51204189) and National Basic Research Program of China (No. 2011CB201202); the authors are grateful for their support. We sincerely thank the editor and anonymous reviewers' who improving this paper. 


\section{REFERENCES}

1. Y. Bufan. Coal mine gas disaster prevention and Utilization Technology Handbook. China Coal Industry Publishing House, 2005.

2. P. Suping, M. Zhaoping, W. Hu, et al.Testing study on por permeability law of sandstone under different confining pressures, Chinese Journal of Rock Mechanics and Engineering 22 (5), 742-746, 2003

3. L. Jianjun, L. Quanshu, Numerical Simulation of Injection Water Flow through Mudstone Interlayer in Low Permeability Oil Reservoir Development, Disaster Advances 10 (4), 1639-1645, 2012.

4. P. Suping, Q. Hongliang, L. Liping, et al. An experimental study on the penetrability of sedimentary rock during the complete stress strain path, Journal of China Coal Society 25 (2), 113-116, 2000.

5. P. Hongyu, Z. Haowei, L. Shugang, et al. Research on Creep Model and Delay Instability of Coal-Rock Containing Gas, Disaster Advances 3 (6), 273-277. 2013

6. W. Jinan, P. Suping, M. Zhaoping, Permeability rule in full strain-stress process of rock under triaxial compression, Journal of University of Science and Technology Beijing 23 (6), 1-3, 2001.

7. H. Gun, Y. Guangzhi, L. Xiaoshuang, Effect of Gas Pressure on the Transport Properties of Outburst-Prone Coal, Disaster Advances 4 (3), 20-23, 2011.

8. Patton, H.F.et al. Simulator for degasification, methane emission prediction and mine ventilation, Fuel and Energy, 36 (1), 4, 1995

9. S. Harpalani, G. Chen, Influence of gas production induced volumetric strain on permeability of coal, Geotechnical \& Geological Engineering 15 (4), 303-325, 1997.

10. T. Jiang, J.F. Shao, W.Y. Xu, et al, Experimental investigation and micromechanical analysis of damage and permeability variation in brittle rocks, International Journal of Rock Mechanics and Mining Sciences 47 (5), 703 -713, 2010.

11. J. Shen, Y. Qin, X. Fu, et al, Relative permeabilities of gas and water for different rank coals, International Journal of Coal Geology 86(2-3), 266-275, 2011.

12. S. Harpalani, R. A. Schraufnagel, Shrinkage of coal matrix with release of gas and its impact on permeability of coal. Fuel 69 (5), 551-556, 1990.

13. L.D. Connell, Coupled flow and geomechanical processes during gas production from coal seams, International Journal of Coal Geology 79(1-2), 18-28, 2009.

14. S. Liu, S. Harpalani, M. Pillalamarry, Laboratory measurement and modeling of coal permeability with continued methane production:Part2- Modeling results. Fuel 94, 117-124, 2012.

15. Z. Si Ning, L. Bo Quan, The theory of gas flow and storage in coal seams. China Coal Industry Publishing House, 2, 1999.

16. F. Zengchao, Z. Yangsheng, Z. Dong, Investigating the scale effects in strength of fractured rock mass, Chaos, Solitons \& Fractals 41(5), 2377-2386, 2009.

17. M. Xiexing, L. Weiqun, C. Zhanqing, Percolation theory of overburden rock stratum. Science Press.2004.

18. H. Xueqiu, L. Mingjv, Electromagnetic dynamics of coal rock containing gas damage, China University of Mining and Technology Press, 5, 1995. 
19. C. Louis, Rock Hydroulics In:Rock Mechanics. L Muller(eds), 1974.

20. D. Kanglian, Z. Wen, H. Yaoqing, Experimental study on the seepage law of coal under the influence of stress and pore pressure, Journal of China Coal Society, 18(4), 43-50, 1993.

21. Z. Yangsheng, K. Tianhe, H. Yaoqing, The permeability classification of coal seam in China, International Journal of Rock Mechanics and Mining Sciences and Geomechanics Abstracts, 32(4), 365-369, 1995.

22. Z. Yangsheng, Rock Fluid Mechanics in Mine, China coal industry publishing house, 12, 1994.

23. L. Shiping, L. Yushou, W. Zhenye, The Permeability-Strain Equations Relating to Complete Stress-strain Path of the Rock, Chinese Journal of Geotechnical Engineering, 2, 13-19, 1995.

24. Y. Yongjie, Basic Expererimental Study on Characteristics of Strength, Deformation and Microseismic under Compression of Coal. Doctoral Dissertation of Shandong University of Science and Technology, 3, 2006

25. Y. Yongjie, C. Jun, H. Dongzhi, et al. Experimental of coal's strain-permeability rate under solid and liquid coupling condition, Journal of China Coal Society, $\mathbf{3 3}$ (7),760-764, 2008. 